\title{
ПРОЦЕССЫ ГЛОБАЛИЗАЦИИ
}

\section{ДЕМОГРАФИЧЕСКИЕ ПРОГНОЗЫ И ГЛОБАЛЬНАЯ ИНТЕГРАЦИЯ В БЛИЖАЙШЕЙ И СРЕДНЕСРОЧНОЙ ПЕРСПЕКТИВЕ}

\author{
Зинькина Ю. В., Шульгин С. Г., \\ Андреев А. И., Алешковский И. А."
}

В статье ставится вопрос о том, как распределяется мировое население между странами с различным уровнем интегрированности в глобальное пространство (в первую очередь экономическое). С использованием демографических проекиий ООН рассчитывается прогноз того, как это распределение будет видоизменяться в ближайшие десятилетия. При этом для определения уровня глобальной интеграџии стран применяется новый подход, основанный на методах сетевого анализа. Сделан вывод о том, что наблюдаемые демографические тенденции способны существенно замедлить рост глобальной интеграции.

Ключевые слова: глобализация, глобальная интеграция, измерение глобализации, измерение глобальной интеграции, уровень глобализаџии, уровень глобальной интеграции, демографические прогнозы.

The paper views the current distribution of the world population among the countries with varying levels of global integration (especially its economic aspect). We use the demographic projections presented by the United Nations to forecast the changes in this distribution over the next decades. The global integration is calculated with a new metrics based on social network analysis. We conclude that the observed demographic trends can cause a slowdown in the global integration processes.

Keywords: globalization, global integration, measurement of globalization, measurement of global integration, globalization level, level of global integration, demographic projections.

* Исследование выполнено при поддержке Российского научного фонда, грант № 17-78-20096.

** Зинькина Юлия Викторовна - к. и. н., старший научный сотрудник Международной лаборатории демографии и человеческого капитала Российской академии народного хозяйства и государственной службы, стажер-исследователь факультета глобальных процессов Московского государственного университета имени М. В. Ломоносова. E-mail: juliazin@list.ru.

Шульгин Сергей Георгиевич - к. э. н., заместитель заведующего Международной лабораторией демографии и человеческого капитала Российской академии народного хозяйства и государственной службы. E-mail: sergey@shulgin.ru.

Андреев Алексей Игоревич - к. б. н., доцент, заместитель декана факультета глобальных процессов Московского государственного университета имени М. В. Ломоносова. E-mail: andreev@fgp.msu.ru.

Алешковский Иван Андреевич - к. э. н., доцент, заместитель декана факультета глобальных процессов Московского государственного университета имени М. В. Ломоносова. E-mail: aleshkovski@yandex.ru.

Век глобализации 1/2018 40-48 


\section{Введение}

В последние десятилетия интерес мирового научного сообщества к явлению глобализации переживает бурный подъем. Среди множества исследований природы глобализации и ее наблюдаемых и предполагаемых последствий особняком стоят относительно немногочисленные исследования, ставящие своей целью измерение глобализации. Тот факт, что попытки измерить глобализацию встречаются в науке не столь часто, как можно было бы предположить, а также то, что до сих пор отсутствует единая общепринятая методика измерения глобализации, следует отнести на счет чрезвычайной сложности и многомерности самого изучаемого явления. Действительно, вполне очевидно, что методика измерения глобализации должна напрямую зависеть от определения этого явления. Подобных же определений в настоящее время в научной литературе существует несколько сотен - это и «сжатие времени и пространства», и «начало безграничного мира», и «идеологический конструкт», и «глобальный торговый центр», и «всемирная интеграция человечества», и «исчезновение национального государства», и «триумф капиталистической мировой экономики», и «макдональдизация мира» [источники определений см.: al-Rodhan, Stoudmann 2006: 41-62]. Видный российский исследователь глобализации А. Н. Чумаков обращает внимание на то, что непрерывные дискуссии продолжаются и вокруг других важнейших понятий, составляющих костяк категориального аппарата глобалистики: глобальные проблемы, глобализм, антиглобализм, глобальный мир, глобальное человечество, интернационализация, глобальная экономика, глобальная политика, глобальная преступность, глобальная культура и т. п. [Чумаков 2014: 41]. В такой ситуации следует понимать, что ответ на любой конкретный вопрос, заданный исследователями глобализации (и даже постановка этого вопроса), будет неизбежно зависеть от выбранного определения глобализации и дискурса ее исследования [Зинькина и др. 2016: 16].

В настоящей работе мы опираемся на понимание глобализации, предложенное выдающимся глобальным политологом и экономистом Дж. Моделски. Оно заключается в сочетании «коннективистского» подхода, рассматривающего глобализацию как увеличение трансграничных взаимодействий, связей и потоков, и институционального подхода, объясняющего глобализацию как возникновение институтов планетарного масштаба ${ }^{1}$ [Modelski 2008]. Следуя этому подходу, мы отобрали ряд глобальных институтов, имеющих сетевую структуру, таких как глобальная торговая сеть, глобальная сеть инвестиций и глобальная сеть миграционных потоков, для того, чтобы построить для них сетевые модели и применить методы сетевого анализа, получая, таким образом, характеристики структурного положения каждой страны в этих глобальных сетях. Эти характеристики затем позволят рассчитать уровень глобальной интеграции каждой страны именно с точки зрения ее сетевых связей, что соответствует подходу Моделски.

Отметим, что в данной работе мы ни в коей мере не претендуем на полноту представленных нами измерений - она является скорее своего рода «приглашением к разговору», исследованием потенциала сетевых методов в измерении уровня

\footnotetext{
${ }^{1}$ Подчеркнем, что термин «институты» Дж. Моделски понимал в этом случае максимально широко, включая в него всемирную свободную торговлю, транснациональные корпорации, глобальное управление, всемирные социальные движения и идеологии и т. д. [Modelski 2008].
} 
глобальной интеграции стран. Даже в экономическом аспекте глобализации к перечисленным нами сетям могут быть добавлены еще некоторые, а те, что мы назвали, могут быть детализированы. Так, глобальную торговую сеть мы подразделяем на две сети - торговли товарами и услугами. Однако теоретически возможны и дальнейшие детализации (к примеру, глобальную миграционную сеть можно разделить на учебную, трудовую и иную миграцию; глобальная сеть трудовой миграции может быть, в свою очередь, разделена на высококвалифицированную и низкоквалифицированную и т. д.). Неохваченными остаются также глобальные сети политических связей и связей социокультурных (хотя к последним в какой-то степени может быть отнесена глобальная миграционная сеть). Тем не менее мы полагаем, что измерение глобальной интеграции стран через сетевые методы даже на ограниченном числе глобальных сетей представляет исследовательский интерес.

Однако еще бо́льший интерес представляют не только сами по себе значения уровней глобальной интеграции, но и их взаимовлияние с другими аспектами глобальной динамики человеческого сообщества. В настоящей статье мы фокусируемся на перспективах взаимодействия глобальной интеграции и демографической динамики в ближайшие десятилетия. Многие мировые исследователи убедительно показывали, что ближайшее будущее ожидается весьма турбулентным с демографической точки зрения - старение населения в первом мире, а также быстрый рост численности населения и образование «молодежных бугров» в ряде беднейших развивающихся стран, согласно прогнозам, могут вызвать значительную турбулентность в сложившемся мировом политическом и экономическом порядке [см., например: Weiner, Russell 2001; Coleman, Rowthorn 2011; Sciubba 2011; Yoshihara, Silva 2012; Apt 2013; Goldstone et al. 2012; 2014; Kim, Sciubba 2015; Teitelbaum 2015]. В этом контексте мы рассматриваем одну из проблем, способных оказать существенное влияние на мировую политическую и экономическую ситуацию, а именно - то, как распределяется в настоящее время мировое население между высоко-, средне- и низкоинтегрированными странами и какие изменения это распределение претерпит в ближайшие десятилетия в связи с прогнозируемыми демографическими изменениями в разных странах.

\section{Данные и методы}

Для исследования применялись данные по глобальной сети торговли товарами (в качестве базовых данных использована статистика импорта в текущих ценах в долларах) [United Nations 2017a], глобальной сети торговли услугами [World Bank 2017], глобальной сети накопленных запасов инвестиций [United Nations 2017a] и глобальной сети накопленных запасов миграции [United Nations 2017b]. Эти четыре сети исследуются на трех временны́х периодах: 2000-2004, 20052009 гг. и с 2010 г. по настоящее время. Демографические прогнозы численности населения различных стран мира взяты по расчетам Отдела народонаселения OOH [United Nations 2017c].

Для каждого периода данные по каждой из сетей были преобразованы в бинарную матрицу, то есть такую таблицу, где столбец А представляет данные о связях страны А с каждой из остальных стран в глобальной сети. Далее использовались методы сетевого анализа, более подробное их описание представлено в других наших работах [см., например: Shulgin et al. 2018]. Здесь лишь отметим 
кратко основную суть: для каждой страны определяется максимально связанное подмножество стран, к которому она принадлежит $\left(\mathrm{k}_{\mathrm{i}}\right)$; затем такое подмножество определяется для всей сети в целом $\left(\mathrm{k}_{\max }\right)$. Далее минимальное число связей одного узла (страны) в первом подмножестве $\left(\mathrm{k}_{\mathrm{i}}\right)$ делится на таковое во втором подмножестве $\left(\mathrm{k}_{\max }\right)$ - это отношение $\left(\mathrm{k}_{\mathrm{i}} / \mathrm{k}_{\max }\right)$ является сетевой характеристикой страны. Например, полученный показатель будет равен 1 , если страна принадлежит к максимально связанному подмножеству сети в целом. Или, например, этот показатель составит 0,5, если максимальная связность страны в 2 раза ниже (слабее), чем максимальная связность сети в целом. Если страна совсем не имеет связей с другими странами, этот показатель для нее будет равен 0 .

Итак, максимальный показатель связности для страны в одной глобальной сети равен 1; соответственно, поскольку мы учитываем 4 сети, суммарный показатель уровня глобальной интеграции страны в нашей метрике составит 4.

\section{Результаты}

В зависимости от значения суммарного показателя уровня глобальной интеграции мы классифицировали страны на 6 категорий (в каждой категории страны перечислены в порядке убывания значений этого показателя):

- «лидеры глобальной интеграции» (страны, имеющие значения уровня глобальной интеграции в диапазоне от 3.99 до 4.00): Великобритания, США, Германия, Италия, Франция, Испания;

- страны с высоким уровнем глобальной интеграции (3.75-3.99]: Нидерланды, Швейцария, Бельгия, Китай, Япония, Канада, Россия, Ирландия, Швеция, Австралия, Польша, Южная Корея, Австрия, Дания, Индия, Бразилия, Сингапур, Норвегия, Гонконг;

- страны с уровнем глобальной интеграции выше среднего (3-3.75]: Турция, Венгрия, Финляндия, Португалия, Чехия, Люксембург, Греция, ЮАР, Таиланд, Малайзия, Румыния, Чили, Израиль, Мексика, Болгария, Новая Зеландия, Словакия, Индонезия, Кипр, Украина, Филиппины, Аргентина, Хорватия;

- страны со средним уровнем глобальной интеграции (2-3]: Пакистан, Египет, Литва, Словения, Латвия, Эстония, Марокко, Объединенные Арабские Эмираты, Мальта, Венесуэла, Нигерия, Иран, Саудовская Аравия, Казахстан, Колумбия, Беларусь, Исландия, Вьетнам, Перу, Уругвай, Кувейт, Панама, Сербия, Бангладеш, Катар, Маврикий, Азербайджан, Алжир, Ливан, Иордания;

- страны с низким уровнем глобальной интеграции (1-2]: Ливия, Шри-Ланка, Бахрейн, Эквадор, Коста-Рика, Грузия, Сирия, Босния и Герцеговина, Тунис, Оман, Македония, Албания, Гана, Молдавия, Бермудские острова, Каймановы острова, Эфиопия, Кения, Йемен, Доминиканская Республика, Ирак, Армения, Боливия, Кыргызстан, Гватемала, Багамские острова, Судан, Кот-д’Ивуар, Танзания, Парагвай, Узбекистан, Замбия, Ангола, Афганистан, Сенегал, Уганда, Виргинские острова, Непал, Камбоджа, Демократическая Республика Конго, Камерун, Сальвадор, Черногория, Мозамбик, Мьянма, Гондурас, Куба, Палестина, Никарагуа, Намибия, Зимбабве, Мали, Того, Тринидад и Тобаго, Бенин, Либерия, Барбадос, Габон, Ямайка, Ботсвана, Буркина-Фасо, Руанда, Мавритания, Малави, Гвинея, Нигер, Макао, Северная Корея, Монголия, Сомали, Таджикистан, Туркменистан, Мадагаскар, Сьерра-Леоне, Бурунди, Белиз, Бруней-Даруссалам; 
- страны с самым низким уровнем глобальной интеграции (0-1]: Свазиленд, Гайана, Лаос, Гамбия, Кабо-Верде, Гаити, Суринам, Эритрея, Папуа - Новая Гвинея, Кюрасао, Аруба, Центрально-Африканская Республика, Чад, Андорра, Экваториальная Гвинея, Лесото, Гвинея-Бисау, Бутан, Южный Судан, Гренландия, Джибути (в эту группу входит также значительное число мелких островных государств и зависимых территорий; для краткости изложения мы не будем их приводить в этом списке; интересующиеся читатели могу ознакомиться с полным списком стран, входящих в эту категорию, по следующей ссылке: https:/drive.google. com/open?id=0B2PD1YBY68PWN0FaRF9faUVtR1k).

Далее мы переходим к анализу распределения мирового населения между выделенными шестью группами стран. Для прогнозирования динамики этого распределения нам необходимы страновые прогнозы численности населения (прогнозные значения населения стран, входящих в определенную группу, суммируются). Мы используем прогнозы, рассчитанные Отделом народонаселения ООН согласно среднему сценарию; горизонт прогнозирования простирается до 2100 г.

Итак, для каждой группы стран мы рассчитываем суммарную численность населения на каждый год в период с 1970 г. по настоящее время (используются данные Отдела народонаселения $\mathrm{OOH}$ ), а также суммарную прогнозируемую численность населения на каждый год с 2018 до 2100 г. Реальная и прогнозируемая динамика численности населения с 1970 по 2100 г. для каждой группы стран представлена на рисунке.

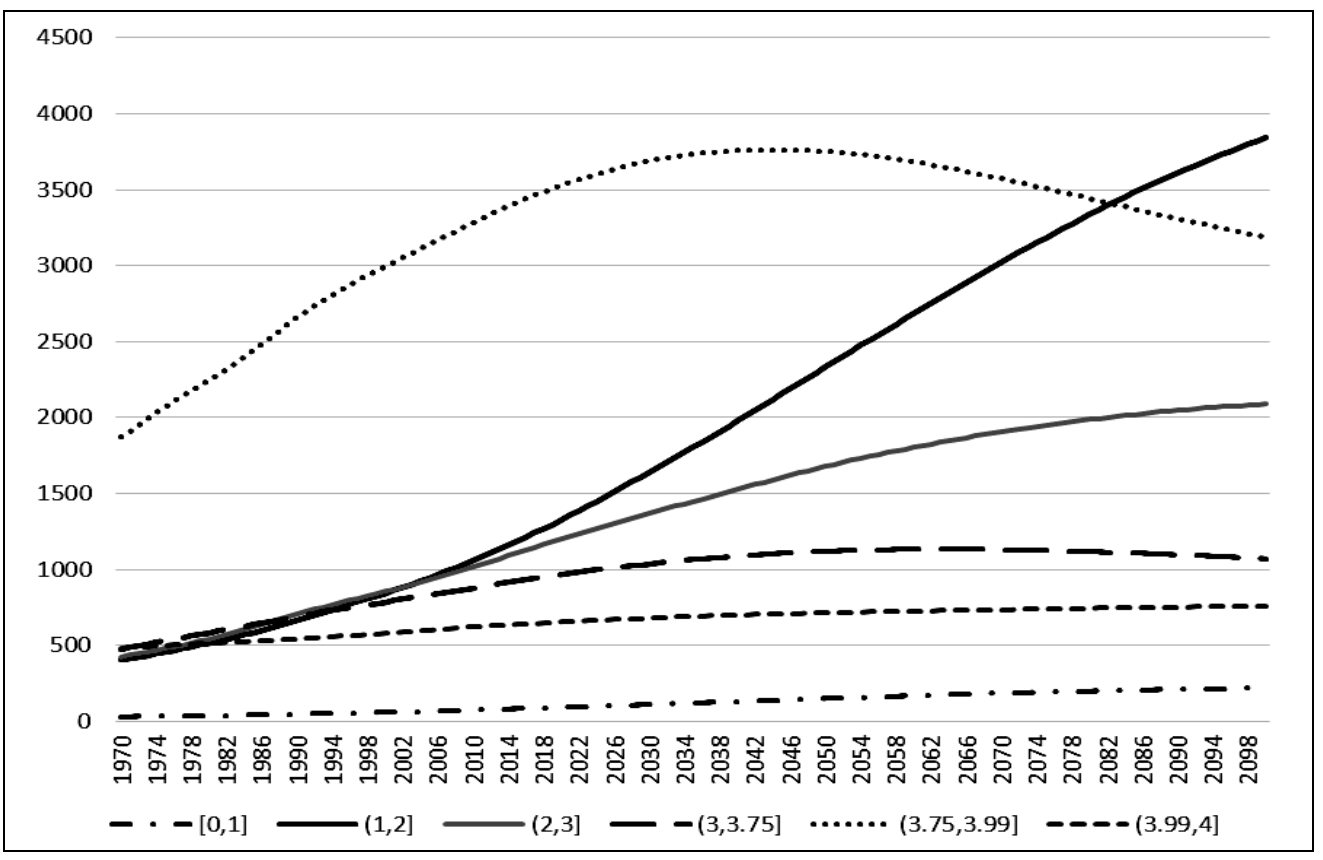

Реальная и прогнозируемая динамика численности населения с 1970 по 2100 г. для групп стран с различными уровнями глобальной интеграции, млн человек

Источник: авторские расчеты по данным и прогнозам (средний сценарий) Отдела народонаселения ООН [United Nations 2017c]. 
Наиболее густонаселенную группу в настоящее время представляют собой страны с высоким уровнем глобальной интеграции, хотя по числу стран эта группа не является самой многочисленной. Этот факт следует отнести в первую очередь на тот счет, что к данной группе принадлежат две наиболее населенные страны мира - Китай и Индия. В целом в странах с высоким уровнем глобальной интеграции сейчас проживает почти половина населения мира (3,46 млрд человек). Второе место (с большим отрывом) по текущей численности населения принадлежит группе стран с низким уровнем глобальной интеграции - в них сейчас проживает 1,15 млрд человек - и группе стран со средним уровнем глобальной интеграции (также 1,15 млрд человек). Группа стран с уровнем глобальной связности выше среднего насчитывает население в 940 млн человек, примерно 640 млн проживают в странах - лидерах глобальной интеграции, и, наконец, 85 млн человек являются жителями наименее интегрированных стран.

Однако анализ демографических прогнозов показывает, что текущее распределение мирового населения по группам стран с различным уровнем глобальной интеграции претерпит весьма значительные изменения в ближайшие десятилетия. Если говорить в общих чертах, то наиболее значимые изменения можно охарактеризовать следующим образом: доля населения, живущего в странах-лидерах, а также в странах с высоким уровнем глобальной интеграции и уровнем выше среднего, снизится уже к 2050 г. и еще сильнее - к 2100 г. Напротив, доля жителей стран со средним, низким и самым низким уровнем глобальной интеграции заметно возрастет (см. таблицу).

Абсолютная численность (млн человек) и относительная доля (\%) мирового населения, проживающего в настоящее время и по прогнозам в группах стран с различным уровнем глобальной интеграции в 2017, 2050 и 2100 гг.

\begin{tabular}{|c|c|c|c|c|c|c|}
\hline $\begin{array}{c}\text { Группа } \\
\text { стран по } \\
\text { уровню } \\
\text { глобальной } \\
\text { интеграции } \\
\end{array}$ & $\begin{array}{c}\text { Население } \\
\text { в } 2017 \text { г., } \\
\text { млн чело- } \\
\text { век }\end{array}$ & $\begin{array}{c}\text { Население } \\
\text { в } 2050 \text { г., } \\
\text { млн чело- } \\
\text { век }\end{array}$ & $\begin{array}{c}\text { Население } \\
\text { в } 2100 \text { г., } \\
\text { млн чело- } \\
\text { век }\end{array}$ & $\begin{array}{c}\text { Население } \\
\text { в } 2017 \text { г., } \\
\text { \% от ми- } \\
\text { рового }\end{array}$ & $\begin{array}{c}\text { Население } \\
\text { в } 2050 \text { г., } \\
\% \text { от ми- } \\
\text { рового }\end{array}$ & $\begin{array}{c}\text { Население } \\
\text { в } 2100 \text { г., } \\
\text { \% от ми- } \\
\text { рового }\end{array}$ \\
\hline Лидеры & 643,4 & 714,3 & 757,9 & 8,7 & 7,3 & 6,8 \\
\hline $\begin{array}{l}\text { Высокий } \\
\text { уровень }\end{array}$ & 3464,1 & 3752,8 & 3186,3 & 46,6 & 38,5 & 28,5 \\
\hline $\begin{array}{l}\text { Уровень } \\
\text { выше } \\
\text { среднего }\end{array}$ & 941,3 & 1118,9 & 1070,2 & 12,7 & 11,5 & 9,6 \\
\hline $\begin{array}{l}\text { Средний } \\
\text { уровень }\end{array}$ & 1146,1 & 1677,9 & 2088,0 & 15,4 & 17,2 & 18,7 \\
\hline $\begin{array}{l}\text { Низкий } \\
\text { уровень }\end{array}$ & 1146,1 & 2331,5 & 3843,2 & 15,4 & 23,9 & 34,4 \\
\hline $\begin{array}{l}\text { Самый } \\
\text { низкий } \\
\text { уровень }\end{array}$ & 85,3 & 149,1 & 218,6 & 1,1 & 1,5 & 2,0 \\
\hline
\end{tabular}

Наиболее выраженный рост населения как в абсолютном, так и в относительном измерении прогнозируется для стран с низким уровнем глобальной интеграции. В настоящее время в них проживает 15,4 \% мирового населения, однако уже 
к 2050 г. этот показатель возрастет более чем в 1,5 раза, а к 2100 г. - более чем в 2 раза. В абсолютном выражении численность населения этой группы стран возрастет более чем вдвое к 2050 г. и более чем в 3 раза - к 2100 г. Напротив, доля людей, проживающих в странах с высоким уровнем глобальной интеграции, согласно прогнозам, значительно снизится (в 1,5 раза к 2100 г.). В абсолютном выражении численность населения стран в этой группе будет расти (постепенно замедляясь) вплоть до второй половины 2040-х гг., а во второй половине столетия несколько снизится. Далее мы рассмотрим некоторые наиболее важные факторы ожидаемых изменений и их возможные последствия для глобального мира.

\section{Обсуждение результатов и заключение}

Для начала рассмотрим саму природу ожидаемых изменений. Важно подчеркнуть, что перераспределение мирового населения между группами стран с различными уровнями глобальной интеграции будет преимущественно происходить не в результате возникновения каких-то колоссальных миграционных потоков, но вследствие того факта, что страны мира находятся на различных стадиях глобального демографического перехода и соответственно темпы естественного прироста и естественной убыли в них сильно различаются. Так, большинство стран с наивысшими и высокими уровнями глобальной связности уже завершили демографический переход (к примеру, европейские государства) либо находятся близко к его завершению (к примеру, Индия). Уровень рождаемости в большинстве этих стран либо примерно соответствует уровню, необходимому для простого воспроизводства населения, либо (весьма нередко) оказывается даже ниже этого уровня. Соответственно, согласно прогнозам, абсолютный прирост населения в ряде государств этих групп окажется небольшим, а во многих странах и вовсе отрицательным (то есть ожидается естественная убыль населения), особенно во второй половине XXI в. Напротив, к группе с низким уровнем глобальной связности принадлежат многие страны (в основном речь идет о государствах Тропической Африки), вступившие в демографический переход с большим запозданием и сохраняющие высокие уровни рождаемости (в ряде государств - более 5 детей на женщину) [см.: Zinkina, Korotayev 2014; Korotayev, Zinkina 2015; Korotayev et al. 2016]. В этих странах чрезвычайно большую долю населения составляют дети и молодежь, а это означает накопление колоссальной демографической инерции; даже если рождаемость в этих странах снизится до уровня простого воспроизводства в ближайшие 10-15 лет (что крайне маловероятно), удвоение абсолютной численности населения в таких странах все равно окажется практически неизбежным [Zinkina, Korotayev 2014].

Итак, с демографической точки зрения значительный рост численности населения, проживающего в странах с низким уровнем глобальной связности, представляется практически неизбежным в ближайшие десятилетия. Однако возможно ли, что эти страны смогут повысить свой уровень глобальной связности и перейти, скажем, в средний или даже в высший эшелон по этому показателю? Различные индексы измерения глобализации, казалось бы, подразумевают, что это возможно - у многих стран уровень глобализации, измеренный через индексы, колеблется от года к году, иногда довольно заметно. Однако подобная волатильность, на наш взгляд, может быть связана с самой природой составления индексов как подхода к измерению глобализации [подробнее см.: Zinkina et al. 2013]. Сете- 
вой подход к измерению глобализации дает несколько более стабильные значения уровней глобальной интеграции (в том числе и за счет того, что значения входящих в него показателей берутся не ежегодные, а за 5-летний период). Разумеется, собственно значения уровней глобальной интеграции различных стран испытывают определенные изменения от одного периода к другому, однако крайне редко эти изменения оказываются настолько велики, чтобы обеспечить переход конкретной страны из одной группы в другую. Так, в период с 2005 г. по настоящее время лишь 2 из 237 стран и территорий - Индия и Сингапур - смогли перейти в группу более высоких значений (из группы выше среднего в группу высоких уровней глобальной интеграции). За почти 20 -летний период, с 2000 г. по настоящее время, переход в более высокую группу смогли осуществить 10 из 237 стран и территорий:

- Бразилия, Россия, Индия, Сингапур - из группы выше среднего в группу высоких уровней глобальной интеграции;

- Румыния, Чили - из средней группы в группу выше среднего;

- Маврикий, Сербия - из низкой группы в среднюю;

- Палестина, Черногория - из самой низкой группы в низкую.

Таким образом, можно видеть, что бо́льшая часть переходов в более высокие группы осуществлялась странами, имеющими уровень глобальной интеграции от среднего и выше. Среди стран, чей уровень глобальной интеграции был ниже среднего, осуществить такой переход смогли лишь 4 государства, причем в трех из них этот переход представлял собой, по всей видимости, не столько выход на новый уровень, сколько восстановительный рост после серьезных военных конфликтов. Из всего вышесказанного следует, что значительное повышение уровня глобальной интеграции той или иной страны представляет собой достаточно медленный и сложный процесс - соответственно, значительная часть стран с низким уровнем интеграции, по всей вероятности, останется в этой же группе в течение ближайших десятилетий. С учетом прогнозируемого в данной группе удвоения численности населения можно предполагать, что заметно бо́льшая доля мирового населения будет проживать в странах с низким уровнем глобальной интеграции, что может повлечь за собой даже определенную деглобализацию и/или рост мирового неравенства по уровню глобальной интеграции. Эти тенденции, безусловно, нуждаются в дальнейшем более глубоком и тщательном изучении. Однако уже сейчас можно с уверенностью заявить, что они должны учитываться при построении разного рода глобальных прогнозов, поскольку эти процессы способны существенно трансформировать привычный нам облик глобального мира.

\section{Лuтература}

Зинькина Ю. В., Ильин И. В., Андреев А. И., Алешковский И. А., Коротаев А. В. Историческая глобалистика. Т. 1. М. : Моск. ред. изд-ва «Учитель», Изд-во Моск. унта, 2016.

Чумаков А. Н. 2014. О глобализации с объективной точки зрения // Век глобализации. 2014. Т. 2. № 14. С. 39-51.

Al-Rodhan N. R. F., Stoudmann G. Definitions of Globalization: A Comprehensive Overview and a Proposed Definition. Geneva : Editions Slatkine, 2006.

Apt W. 2013. Germany's New Security Demographics: Military Recruitment in the Era of Population Aging. N. p. : Springer Science \& Business Media, 2013. 
Coleman D., Rowthorn R. Who's Afraid of Population Decline? A Critical Examination of its Consequences // Population and Development Review. 2011. Vol. 37. No. s1. Pp. 217-248.

Goldstone J. A., Kaufmann E. P., Toft M. D. (Eds.). Political Demography: How Population Changes are Reshaping International Security and National Politics. Oxford : Oxford University Press, 2012.

Goldstone J. A., Marshall M. G., Root H. Demographic Growth in Dangerous Places: Concentrating Conflict Risks // International Area Studies Review. 2014. Vol. 17. No. 2. Pp. 120-133.

Kim T., Sciubba J. D. The Effect of Age Structure on the Abrogation of Military Alliances // International Interactions. 2015. Vol. 41. No. 2. Pp. 279-308.

Korotayev A., Zinkina J. East Africa in the Malthusian Trap? // Journal of Developing Societies. 2015. Vol. 31. No. 3. Pp. 385-420.

Korotayev A., Zinkina J., Goldstone J., Shulgin S. Explaining Current Fertility Dynamics in Tropical Africa from an Anthropological Perspective: A Cross-Cultural Investigation // Cross-Cultural Research. 2016. Vol. 50. No. 3. Pp. 251-280.

Modelski G. Globalization as Evolutionary Process // Globalization as Evolutionary Process: Modeling Global Change / Ed. by G. Modelski, T. Devezas, W. R. Thompson. London; New York : Routledge, 2008. Pp. 11-29.

Sciubba J. D. The Future Faces of War. Population and National Security. Santa Barbara, CA : Praeger, 2011.

Shulgin S., Zinkina J., Andreev A. Measuring Globalization: Network Approach to Countries' Global Connectivity Rates and Their Evolution in Time // Social Evolution and History. 2018. No. 2. Forthcoming.

Teitelbaum M. S. Political Demography: Powerful Trends Under-attended by Demographic Science // Population Studies. 2015. Vol. 69. Sup. 1. Pp. S87-S95.

United Nations. 2017a. UN Comtrade Database [Электронный ресурc]. URL: https:// comtrade.un.org/ (дата обращения: 10.07.2017).

United Nations. 2017b. International Migrant Stock 2015. International Migrant Stock by Destination and Origin [Электронный ресурc]. URL: http://www.un.org/en/development/ desa/population/migration/data/estimates2/estimates15.shtml (дата обращения: 17.07.2017).

United Nations, Department of Economic and Social Affairs, Population Division. 2017c. World Population Prospects: The 2017 Revision [Электронный pecypc]. URL: https://esa.un.org/unpd/wpp/ (дата обращения: 31.07.2017).

Weiner M., Russell S. S. (Eds.). Demography and National Security. New York, NY : Berghahn Books, 2001.

World Bank. 2017. Trade in Services Database [Электронный pecypc]. URL: https:// data.worldbank.org/data-catalog/trade-in-services (дата обращения: 24.07.2017).

Yoshihara S., Sylva D. A. (Eds.). Population Decline and the Remaking of Great Power Politics. Washington, DC : Potomac Books, Inc., 2012.

Zinkina J., Korotayev A. Explosive Population Growth in Tropical Africa: Crucial Omission in Development Forecasts-emerging Risks and Way out // World Futures. 2014. Vol. 70. No. 2. Pp. 120-139.

Zinkina J., Korotayev A., Andreev A. Measuring Globalization: Existing Methods and Their Implications for Teaching Global Studies and Forecasting // Campus-Wide Information Systems. 2013. Vol. 30. No. 5. Pp. 321-339. 